\title{
E-Learning in a Financial Institution
}

\author{
Kety Jáuregui \& Rafael Andreu \\ University of Navarra, Barcelona, Spain
}

\author{
Jauregui@iese.edu Andreu@iese.edu
}

\begin{abstract}
This paper examines how information technology is used in training. It also analyzes the consequences when a particular financial institution based in Barcelona starts to use new technologies to deliver a training program aimed at providing basic knowledge of the business to new employees joining the branch network throughout Spain.

From our study, we conclude that there is great potential in the use of new technologies in training. They are being used to exchange (deliver and receive) the course materials, including syllabus, tasks and theoretical content, and as a means of interaction between participants and teachers, and among participants. However, implementing such an online communication system is not very easy, for instance, developing virtual communities of formal and non-formal learning, obtaining adequate course coherence when combining face-to-face and virtual learning, creating virtual courses based on real cases, and having in-house employees as on-line tutors.
\end{abstract}

\section{Introduction}

Over the last four decades, globalization, deregulation and other changes in the environment have changed the competitive structure of markets. In this new environment, firms are more aware than ever that their survival depends on their capacity to respond rapidly to the environment's opportunities and threats, and that this capacity lies in their employees. This is why firms need their employees to continuously acquire new knowledge and skills, and develop their individual capacities, in particular. Accordingly, firms have come to see learning and training as powerful competitive weapons and as an essential tools for adapting to the changing environment.

Traditional training appears to be incapable of meeting these expectations, Hope and Hope (1997) state that training process is too long and covers too many subjects: it is unfocused, non-pertinent, non-adaptable to employees, or dated. Furthermore, when teachers and learners are geographically distant, it is costly to gather them in a single location due to travel and accommodations limitations (logistics, personnel-coordination, expenses etc.), as well as the loss of man-hours when employees attend training programs. Faced with this situation, firms are investing in new technologies in search of new learning models that will help to make their training programs more effective and less expensive.

Previous studies (Arbaugh JB, 2000; Almeda \& Rose, 2000) have shown some of the ways in which these new

Material published as part of these proceedings, either on-line or in print, is copyrighted by Informing Science. Permission to make digital or paper copy of part or all of these works for personal or classroom use is granted without fee provided that the copies are not made or distributed for profit or commercial advantage AND that copies 1) bear this notice in full and 2) give the full citation on the first page. It is permissible to abstract these works so long as credit is given. To copy in all other cases or to republish or to post on a server or to redistribute to lists requires specific permission from the publisher at Publisher@InformingScience.org technologies can contribute to training. New technologies allow the delivery of training "anytime, anywhere", through an effective and fast "just-in-time" mode (Masie, 1999) and taking into account the needs of employees. They can also bring improvements in content presentation and new ways of capturing the learner's attention, as well as different ways 


\section{E-Learning In A Financial Institution}

to develop perception, memory and comprehension. Furthermore, they allow learners to access documents in a non-linear way, without the constraints present in the use of textbooks (Shohreh \& Garland, 2000). Up to now, there has not been time to study this issue through empirical research, taking different environments into account, because it is such a new issue and because advances in Internet technology are only just starting to allow the implementation of virtual learning environments.

It is within this context that this case study undertakes to investigate a training program delivered to the newly recruited staff of a Spanish savings bank headquartered in Barcelona. The study describes and analyzes the outcomes resulting from the use of information technology in the design, development and delivery of training.

The study begins with a short introduction to new technology-based training. The company background is presented and the different training methods it uses are described. Next, the training method traditionally used for new employees is studied and its constraints are pointed out. After that, the inception of the virtual campus is discussed and the program's contents are described. The learning process on this campus is explained and the average participant's profile is described. The tutor's profile and duties are commented upon and interactions within the campus are explained, concluding with a discussion of course design and development. Lastly, an analysis of the most important issues covered in the essay is presented, ending with the conclusions.

\section{The Firm}

Caja de Ahorros y Pensiones de Barcelona ("la Caixa") was founded in July 1990 as a result of the merger between Caja de Ahorros y Monte de Piedad de Barcelona, founded in 1844, and Caja de Pensiones para la Vejez y de Ahorros de Cataluña y Baleares, founded in 1904. One of its main purposes is to finance and support social, cultural, educational and scientific activities. $30 \%$ of the profits are used to finance this type of activities through the "Fundación la Caixa" foundation.

la Caixa's growth in recent years has been impressive, making it one of the flagship banks of the Spanish financial sector. The business model it has adopted, that of the "universal bank", implies the ambition to offer the best and most comprehensive services to the largest possible number of clients. To do this "la Caixa" has three basic features. Firstly, management decentralization in the main and regular branches through having most of its staff assigned to sales activities, thus maintaining a ratio of central services employees to total workforce of $6.7 \%$. Secondly, a branch expansion plan outside Catalonia and the Balearics, initiated 10 years ago, to give the bank a greater presence in the rest of Spain and so remove physical barriers and facilitate relations with customers (200 branches were opened and 1500 new jobs were created in 2000). Thirdly, intensive use of information technologies and communications to simplify administrative tasks, and the introduction of other cha nnels to reach customers, such as Internet banking.

\section{Training}

Given its business concept and banking model, "la Caixa" regards its employees as the key factor for putting its service philosophy into effect. Accordingly, it places great emphasis on training.

Two types of training are used: (1) Continuous education; (2) Programs for new employees. Continuous education is basic learning for those who have worked in the bank for several years. It is delivered face-to-face and in accordance with the needs of each main branch. Customized training is provided because every location is different, and has different circumstances.

The program for new employees consists of basic training in the banking business and the products offered by "la Caixa". It is delivered in a combination of face-to-face and virtual mode. The face-to-face lessons are in- 
tended to allow the tutor to share business experiences with the participants. Virtual lessons are delivered through tutorials and offer basic and descriptive knowledge about commercial aspects of the business. The program has included seven face-to-face lessons, each lasting two days and offered approximately every month and a half. The first face-to-face lesson is considered the most important as it includes a presentation of the training program, the way the virtual campus operates and information on the tutor. During this first meeting, tutors seek to develop an atmosphere of trust in order to facilitate later interaction. It lasts for one year, corresponding to the trial period for new employees. Upon completion of the program, a full contract is offered if both sides, the employee and "la Caixa", agree.

\section{Traditional Training for New Employees}

Training of new employees started in 1990 using a mixed face-to-face and traditional distance education model. The program lasted 300 hours and both the face-to-face and the traditional distance modes were provided by a consultancy agency. The traditional distance education component consisted of the learners receiving printed materials (a "load" of material, in the words of the learners) or a compact disk (CD-ROM) containing "la Caixa's" product and service manuals. They studied this material and then communicated with their tutor in a very limited way using the available tools (traditional mail or, in the best of cases, telephone).

This type of distance education had several limitations: firstly, employees learned by themselves and the technology available allowed little or no interaction with the tutor, which left the learner with certain doubts. Secondly, there are problems with the contents because it is set in the fast-moving environment of the financial industry, characterized by highly volatile products and services and very changeable laws and regulations. They could not be updated and delivered fast enough, so many of the CD-ROM courses soon became obsolete and sometimes employees studied material that was out of date. Thirdly, the costs of developing and updating CDROM courses were high because they were generally edited using multimedia support. Finally, end-of-course evaluations did not include feedback; tutors just sent the exam grades, so learners were not encouraged to make improvements or change.

\section{Inception of the Virtual Learning Campus}

In view of these limitations, an e-learning project was developed to replace distance education by creating a virtual learning campus, named virt@ula. The first specific aim of the project was to offer facilities that would enable better induction and integration of new employees in the branch network. Thus, the Director spoke of the virt@ula project in the following terms:

"The challenge we have on our hands is to give all this flow of people joining the bank the basics for a year, so as to enable them to develop their professional and personal careers within the organization."

A second objective was to develop a shared virtual space where teamwork could be promoted, as well as to develop formal and informal virtual learning communities. Based on this concept, classroom and global forums were created, giving rise to a considerable flow of information. We quote what the Project Director stated on this issue:

"There are many unsupervised exchanges of personal messages through which information flows; they may be formal or informal, relevant or irrelevant. And they lead to the creation of lasting ties, a sense of belonging to a community that goes beyond the formal relations among employees." 


\section{E-Learning In A Financial Institution}

A third goal was to enable the virtual campus to support organizational development by creating new ways of doing things, learning, interacting and collaborating. In addition, the virtual campus was expected to generate cultural change, as participants would work in virtual teams. In the words of the Project Director:

"With virt@ula we are knocking down technology barriers; we are developing a new kind of literacy, which is extremely important for 'la Caixa's' culture."

A fourth objective was to turn the virtual campus into a managerial tool for change, particularly in branches located far from the main towns and cities and with very few employees (less than four on average). New employees were constrained by the closed environment and the lack of external models that might help them to become more effective in their work.

A fifth objective was to keep the course contents easily updated through instantaneous delivery and at a lower cost than in traditional distance education.

This project, which was initiated in Catalonia and the Balearics in January 2000, included a pilot program for 100 participants, divided into five virtual classrooms and supported by three tutors. The program was subsequently extended to the whole of Spain, reaching all employees in the branch network. As of December 2001, it has 1,500 participants, 130 virtual classrooms and thirty-four tutors.

\section{What Employees Learn at virt@ula}

At virt@ula, participants mainly learn concepts related to the business of banking through short case studies (called "activities"). Learners have two compulsory course blocks: Itinerary and Generic Contents.

The Itinerary block includes topics on the products and services that "la Caixa" offers to its clients. It comprises six modules: Income tax and project taxation, Liabilities, Services, Electronic banking, Insurance and Assets.

The Generic Contents block deals with issues such as taxation, economic theory and legal aspects of banking operations, though not directly related to "la Caixa's" products and services. Each module lasts approximately one month and a half. Learners follow these courses according to a flexible calendar that takes into account the programming of the face-to-face component; completion of the virtual component is required before taking the face-to-face sessions. Nevertheless, learners can jump ahead in some subjects if, for example, there is a credit card campaign in their branch or they need to complete the income tax course before May, when the tax campaign starts in Spain.

In addition, there are several optional self-training courses that can be completed whenever the learner wishes. They cover very basic general topics such as the Internet, negotiations and communications. These courses are non-tutor-guided, but the negotiations and communications topics are discussed during the face-to-face meetings.

It is worth mentioning that none of the courses are graded. Recruitment decisions with respect to each employee depend on performance and are taken by the head of the branch in which the employee works. As the Director of the virt@ula project explained:

"Exams do not mean anything to us; what matters is good job performance and I think we are attaining that." 


\section{How do Employees Learn at virt@ula?}

Learning is based on the discussion of five or six case studies for each course, each of which has to be solved individually and then discussed in the discussion forums in the virtual classroom. If learners are unsure of anything, they can resort to the reference material that explains the basic concepts of the business. Comple ting each of these activities can take up between 10 minutes and two hours.

Tutors send feedback on each activity in each virtual classroom after learners have posted their responses in the forums. They do so by compiling the main ideas included in the responses sent to the forums. This is done when the time limit for the completion of each activity is reached and serves as a way to close the forum. In addition to this general feedback sent to the class as a whole, tutors can send personal comments to each learner's mailbox, thus avoiding hurting their feelings or discouraging them if they had problems with the activity. This is important as it encourages trust towards the tutor and guarantees confidentiality.

It should be pointed out that earlier courses were based on theoretical textbooks containing self-assessment exercises. Course content have been modified in light of feedback from learners and tutors to the effect that the contents were too theoretical and offered no scope for activities that exercise the learner's reasoning abilities.

Although each learner has his or her own learning style, certain general patterns have been observed. Some learners do all the activities and read all the reference material on- screen, while others read the activities or reference material on-screen and make handwritten notes on the important issues or print them out, and others print out all the activities and reference material because they find it easier to have the information on paper rather than reading it on-screen. That way, also, they do not need to make notes because they can highlight the main points on the paper. It has been found that participants still have not acquired the habit of taking notes on the electronic notepad, although they are encouraged to use all the options facilitated by the virtual campus. The screen tires their eyes and working with the computer does not help them assimilate what is being studied. This confirms the findings of Wade \& Power (1998) with regard to people's preference not to read from a computer screen. Other participants consider that the reference materials are too important or too long to read from the screen, and so prefer to print them out.

Additionally, tutors include non-compulsory extra activities in the modules contained in the discussion forums, as a complement to the main activities and/or as a means of promoting interaction among learners when there is little interaction taking place in the virtual classroom. Such complementary activities might include discussing changes that could be implemented in the branches to improve customer service.

\section{Participants}

Participants are young people between the ages of 22 and 28, with professional diplomas or degrees in various subjects (economics, law, tourism, etc.) and interested in pursuing a career in the financial environment. For most of them "la Caixa" is their first employer. They are enthusiastic and satisfied with the job and training they are being offered. As "la Caixa" is a model institution in the Spanish financial sector, participants see the induction process as a challenge; they value opportunities highly and feel that the future is in their hands. The strong motivation among students may be one reason why the technology-based learning model has been so successful. Hiltz (1986) sustains that motivation is an important factor in attaining positive learning through technology.

Learners have reported that they do the virt@ula courses in the evening after work or at the weekend, either in the office or at home. They study for an average of one-and-a-half to two hours a week, although some of them say they may work up to 10 hours during a holiday. One learner confided: 


\section{E-Learning In A Financial Institution}

"I try to access the classroom from home at least one or two hours a week, so that I don't get stressed."

One of the main advantages that learners find in virt@ula is flexibility. As there are no schedules, they can fit their learning in with their work and their private life. As one of the learners explained:

"Doing it whenever you feel like doing it, that's the best thing about it. When Sunday comes, you may feel it's the right time, so you log on, or perhaps on a Saturday night, when you aren't in a rush."

It is important to point out that a study conducted by Arbaugh (2000) found that participants perceive the flexibility offered by the Internet as one of the main advantages of this type of training.

Another advantage for learners is that they can learn at their own pace, as they have control over the contents that need to be covered. They can move ahead to a new concept or back to a previous one at any time, or they can do an entire course again if they feel the need. This allows them to devote more time to specific topics if they are unfamiliar with the banking business, either because they come from a different educational background or simply because they do not understand it very well. This is consistent with Knowles' theory (1998), which says that adults take up self-directed learning because mature people are more independent and selfregulated.

Participants find the mixed face-to-face and virtual method very helpful for this type of training and consider that it is a good way to be inducted and integrated in "la Caixa". They feel that it is easier to learn in the face-to-face lessons when they are delivered after the virt@ula lessons, as they have already gained a theoretical foundation that brings them up to the basic level. They also think that it would not be sufficient to have only face-to-face lessons, owing to the amount of "theory" they need to know beforehand. Likewise, if there were only virtual lessons, the course would be too difficult and dense. As one participant commented:

"I found that e-learning is very good when it's complemented by face-to-face training. Just having faceto-face lessons would have been too hard to follow because of the fixed timetables. And having only elearning would have been hard, too. The combination is great."

Participants very often get frustrated at the slowness of the Internet, and especially the time it takes to download the images contained in the self-training courses and the limited capacity of their office computers. In spite of this, they have to continue under these negative conditions. This confirms Hiltz's (1986) observations regarding the personal effort and willingness students need to put into learning through technology, as technological constraints can spoil the learning experience.

\section{Tutors}

Tutors are the people that accompany participants throughout the learning process. The typical profile is that of a branch manager or deputy manager who has previously been a face-to-face instructor. They are well acquainted with "la Caixa's" culture and have a great deal of experience in banking. They are the people that know best how to do the job, as they know the day-to-day running. One tutor made the following observation:

"To deliver this type of training, you need to be involved in what the learners will have to do or are already doing. What I mean is that if tutors are merely instructors, they won't have the experience of dayto-day circumstances that do not fit in with the theory and lead to failures, and that is not easy to transmit."

It is worth noting that Ulrich \& Greenfield (1995) recommend the firm's in-company executive members as the most appropriate tutors for this learning model. 
Tutors are people who believe that the Internet has great potential as a vehicle for learning and is where the future of learning lies. Moreover, they convey their enthusiasm for working with the Internet by using Internet technology as the only means of communication and replying to e-mails daily, among other things. Tutors' positive attitude towards technology can yield better results in the learning process (Webster \& Hackley, 1997).

A tutor's main functions are to: facilitate and motivate learning, assure that participants stick to the course calendar, manage regular electronic correspondences with the participants, actively participate in discussion forums, propose activities for the forums in order to promote debate and foster interaction among participants. It should be noted that previously the tutor's role was too passive, helping slow students only when asked. "Before it was like that," commented the Director of virt@ula, "because at the beginning nobody knew what an on-line tutor was supposed to do. At present, the tutor plays a very active role and is one of the main pillars of the virtual learning model. This new definition of the tutor's role was reached through practice; we 'visualized' it as we went along. In fact, it started to emerge during meetings at which we exchanged ideas about the experience gathered so far.

Most tutors agree that they are very pleased with the experience of being on-line tutors, in spite of the workload it involves. Almeda \& Rose (2000) state that on-line teachers devote much more time to virtual teaching than is the case in traditional teaching because they need to send individual e-mail messages, students expect more help than is offered in class and e-mails need a prompt reply.

Also, tutors have other activities in order to help students improve their performance. For example, every six months, tutors attend intensive seminars organized by the project management. Each lasting three or four days, these seminars are aimed at sharing experiences, discussing achievements and improving the learning model.

\section{Interaction}

Interaction is positively associated with a student's satisfaction with the course (Arbaugh, 2000). The Director of the project comments that interaction is a key element in virt@ula because the virtual learning model basically involves "working in teams, sharing experiences and learning from success", and this is attained through interaction.

Two kinds of interaction can be distinguished: (1) Formal interactions, relating to the courses, (2) Informal interactions, carried out by participants on any other topic apart from the course.

Formal interaction mainly occurs when participants contact their tutors by e-mail with queries about course contents, schedule, technical problems or other matters, or when participants post answers to regular course activities or extra activities from the discussion forums, and also when tutors send their final commentary. Another type of formal interaction between tutors and participants takes place when tutors call for a virtual meeting by chat to discuss a particular topic. This type of interaction tends not to be very successful as not all learners are able to participate due to time and Internet connection speed constraints. This tallies with Almeda \& Rose's (2000) observations regarding the limited use of chat in courses, due to the low level of student participation.

Informal interaction mainly takes place among participants in the global discussion forum, which is an open space for the virt@ula community. At the global forum, the students discuss on informal topics such as films, football, cars, jokes, etc. They perceive this forum as a leisure place that they like to access because it is always updated with current issues. Also, the forum serves as a bulletin board for posting general ads addressed to the community in general. The role of the bulletin board in facilitating contact between physically distant people is important because promoting confidence, collaboration and a sense of identity within "la Caixa". There is also informal interaction when participants connect to the campus to study and find a peer or acquaintance to chat 


\section{E-Learning In A Financial Institution}

with about various topics, not necessarily the courses. This interaction takes place through the "What's up?" option (virt@ula's chat-room). Note that participants consider the first face-to-face meeting as the most important one because they can meet personally before interacting on-line, thus strengthening their friendship and developing trust.

\section{Course Design and Development}

Gagné (1986) has identified a number of learning conditions that are important in designing courses to facilitate positive learning in students. Gaining attention and making course objectives explicit are crucial prerequisites. Thus, technological means are used to offer courses at virt@aula, an attractive presentation with colors and visual effects to capture participants' attention. The objectives and the average time that each course activity will demand are presented through hypertext. Also, the online courses have a standard design, coherent navigation styles, icon locations, etc. Sound and video graphics are used as they very often lead to slowness of online connections \& communications, due to the prevailing technological constraints.

Hypertext is used to link contents and this facilitates non-linear navigation. For instance, participants can leave an activity they are currently engaged in to refer to resource materials and then go back to the activity; this helps them to grasp relations between concepts and get a better understanding of what is being taught. Hypertext has a positive effect on constructivist learning, enabling students to take a more active role, as it is up to them to construct their own knowledge (Shohreh \& Garland, 2000). Constructivist approach consists of providing learners with multiple world perspectives (Jonassen, 1991).

A great majority of the online (?) courses are quite short because participants think that the longer the course, the more material they will have to review. They also feel that they will get lost if they try to study too much material and theirs acknowledged that this may represent a psychological barrier. Since January 2001, courses can be printed out at students' request, as some of them are very long.

The itinerary courses are created internally during workshops attended by tutors, branch managers and deputy managers, as well as for employees with broad experience. This method of content creation is very important because it means that the resulting courses are based on concrete daily problems that can arise in any branch. This gives participants examples of real-life situations and, at the same time, allows tutors to develop their own "expertise". In addition, external expert consultants in the field develop generic content courses.

\section{Discussion}

This use-case reveals some interesting applications, along with some definite limitations of the new online learning technologies.

First, technology can support some of the activities in the learning process, notably:

a) Course material distribution through the Web, including syllabus, course activities or theoretical course contents;

b) Interaction between participants and educators through discussion forums - participants can raise queries with the community as a whole, send activity answers to their tutors or share insights with the community, and likewise, educators can give participants feedback on their work;

c) Interaction between participants and educators through e-mail - participants send their queries to tutors on any course topic or technical subject, and tutors send students their answers. We have observed that 
the type of communication used is asynchronous, which can be an advantage compared with face-toface training. It seeks to let participants follow the course and interact in a flexible way.

Secondly, technology may aid reflection process. Ertner \& Newby (1993) find that reflection is considered a vital part of the learning process. In order to communicate with their peers and tutors through the discussion forums and e-mail, participants go through a reflection process while attempting to express an idea in writing. Interestingly in our study as well, participants reported that when they post the answers to the activities in the classroom forum or send queries to their tutor via e-mail, they actually think more about what they are writing and this helps them consolidate their knowledge.

Thirdly, the combination of virtual and face-to-face training can be more effective than using only the virtual method. As the program is intended for new recruits to the firm, face-to-face sessions are very important to give them a chance to meet each other personally and also to meet senior employees in the firm. In our study, we have observed that this creates stronger bonds of trust among them, which later result in greater participation in the virtual campus and a better working environment.

Fourth, there are technological constraints that limit the scope for reliable synchronous communication, so it is not advisable to use chat for an entire session or for formal communication.. In our study, we have observed that chat does not contribute much to flexibility, and the advantage of e-learning is flexibility.

Fifth, tutors face some problems when managing interaction within discussion forums, due to the quantity and variety of inputs from the participants as it is difficult for them to sum up all the discussions. To solve this problem, some tutors divided the virtual classroom of approximately 50 students into groups, in order to form forums and thus obtain a manageable number of opinions. This makes it easer to sum up the final group opinions and gives greater weight to individual points of view (as well), perhaps first with group conclusions and then with conclusions for the entire virtual classroom. However, it would be useful to research other ways of managing this great quantity of interactions.

\section{Conclusions}

The results of this study suggest that there is potential for the application of new technologies to education. However, this potential is sometimes diminished by inconveniences, such as technological limitations - slow Internet connections, the amount of time tutors have to dedicate to the program, the level of commitment and effort required of participants compared to traditional training. As it is a new mode of learning, firms gain experience gradually as they develop and implement courses.

Training programs using new technologies have evolved gradually. In the case of "la Caixa", courses started with a very basic learning design that consisted of transferring materials previously used in the traditional distance learning courses to digital format. At that time, communication between participants and tutors, or among participants, was done mainly through e-mail. Later, courses were improved by adding facilities offered by new technology, such as non-linear links, pictures, graphics, interactivity through discussion forums, and so on. These facilities have been added as the company gained experience, drawing on the suggestions of participants and tutors, the outcomes of tutor meetings and the synergies identified during the process.

Although this study cannot be generalized to other types of training programs, such as continuous learning courses, we feel that the results have important implications. They are relevant to those firms that are switching some of their training programs to the e-learning model, and also for researchers interested in studying the impact of new information technologies on learning. 


\section{Acknowledgement}

We are most grateful to Sandra Sieber and Bishwajit Choudhary for their constructive suggestions.

\section{References}

Almeda, Mary \& Rose, K. (2000). Instructor satisfaction in University of California extension's on-line writing curriculum. Journal Asynchronous Learning Networks 14(3).

Arbaugh, J.B. (2000). Virtual classroom characteristics and student satisfaction with Internet-based MBA courses. Journal of Management Education. 24(1): 32-54.

Ertner, P. \& Newby, T. (1993). Behaviorism, cognitivism, constructivism: Comparing critical features from an instructional design perspective. Performance Improvement Quarterly, 6(4): 50-72.

Gagné, M. (1985). The conditions of learning and theory of instruction ( $4^{\text {th }}$ ed.), Forth Worth: Holt, Rinehart and Winston.

Hiltz, S. (1986). The virtual classroom: Using computer-mediated communication for university teaching. Journal of Communication 36 (2): 95-104.

Hope, J. \& Hope, T. (1997). Competing in the third wave. Harvard Business School Press.

Jonassen, D. (1991). Objectivism versus constructivis: Do we need a new philosophical paradigm? Educational Technology Research \& Development, 39(3): 5-14.

Knowles, M., Holton, E. \& Swanson, R. (1998). The adult learner. The definitive classic in adult education and human resource development. Houston: Gulf Publishing Company. Ed. Holton.

Jarvenpaa, S. \& Leidner, D. (1993). The information age confronts education: Case studies on electronic classrooms. Information Systems Research, 4(1): 24-54.

Masie, E (1999, April). TechLearn TRENDS (119). http://www.masie.com

Shohreh, K. \& Garland, K. (2000). Development of a Web-based Internet marketing course. Journal of Marketing Education 22(2): 8489.

Ulrich, D. \& Greenfield, H. (1995). The transformation of training and development to development and learning. American Journal of Management Development 1(2): 11-22.

Wade, V. \& Power, C. (1998). Evaluating the design and delivery of WWW based educational environments and cours eware. Proceedings of the 6th annual conference on the teaching of computing. A s sociation for Computing Machinery.

Webster \& Hackley. (1997). Teaching effectiveness in technology-mediated distance learning. Academy of Management Journal. 40(6) 1282-1309. 